\title{
Rewarding Effects of Optical Stimulation of Ventral Tegmental Area Glutamatergic Neurons
}

\author{
Hui-Ling Wang, Jia Qi, Shiliang Zhang, ${ }^{-H u i k u n ~ W a n g, ~ a n d ~ M a r i s e l a ~ M o r a l e s ~}$ \\ Neuronal Networks Section, National Institute on Drug Abuse, National Institutes of Health, Baltimore, Maryland 21224
}

Ventral tegmental area (VTA) neurons play roles in reward and aversion. The VTA has three major neuronal phenotypes: dopaminergic, GABAergic, and glutamatergic. VTA glutamatergic neurons - expressing vesicular glutamate transporter-2 (VGluT2) — project to limbic and cortical regions, but also excite neighboring dopaminergic neurons. Here, we test whether local photoactivation of VTA VGluT2 neurons expressing Channelrhodopsin-2 (ChR2) under the VGluT2 promoter causes place preference and supports operant responding for the stimulation. By using a Cre-dependent viral vector, ChR2 (tethered to mCherry) was expressed in VTA glutamatergic neurons of VGluT2::Cre mice. The mCherry distribution was evaluated by immunolabeling. By confocal microscopy, we detected expression of mCherry in VTA cell bodies and local processes. In contrast, VGluT2 expression was restricted to varicosities, some of them coexpressing mCherry. By electron microscopy, we determined that mCherry-VGluT2 varicosities correspond to axon terminals, forming asymmetric synapses on neighboring dopaminergic neurons. These findings indicate that ChR2 was present in terminals containing glutamatergic synaptic vesicles and involved in local synaptic connections. Photoactivation of VTA slices from ChR2-expressing mice induced AMPA/ NMDA receptor-dependent firing of dopaminergic neurons projecting to the nucleus accumbens. VTA photoactivation of ChR2expressing mice reinforced instrumental behavior and established place preferences. VTA injections of AMPA or NMDA receptor antagonists blocked optical self-stimulation and place preference. These findings suggest a role in reward function for VTA glutamatergic neurons through local excitatory synapses on mesoaccumbens dopaminergic neurons.

Key words: addiction; aversion; dopamine; reward; VGluT2; VTA

\section{Significance Statement}

We show that previously discovered glutamatergic neurons within the ventral tegmental area (VTA), through their local connections, play a role in reward. The participation of VTA glutamatergic neurons in reward involves VTA glutamatergic neurons that establish local excitatory connections. These neurons concentrate the protein VGluT2 in their axon terminals to transport and accumulate glutamate into vesicles for its synaptic release. The VTA activation of these terminals is rewarding and involves local synaptic glutamate release, which in turn activates glutamatergic receptors in neighboring mesoaccumbens dopaminergic neurons.

\section{Introduction}

Subsets of ventral tegmental area (VTA) neurons are involved in motivated behaviors. Some of them participate in reward processing, and others participate in aversive processing. The behavioral involvement of VTA neurons appears to depend on their molecular phenotype and projection targets. Optogenetic studies

Received Sept. 13, 2015; revised 0ct. 27, 2015; accepted 0ct. 27, 2015.

Author contributions: H.-L.W., J.Q., S.Z., H.W., and M.M. designed research; H.-L.W., J.Q., S.Z., H.W., and M.M. performed research; H.-L.W., J.Q., S.Z., H.W., and M.M. analyzed data; H.-L.W., J.Q., S.Z., H.W., and M.M. wrote the paper.

The Intramural Research Program of the National Institute on Drug Abuse supported this research.

The authors declare no competing financial interests.

Correspondence should be addressed to Marisela Morales, National Institute on Drug Abuse, Intramural Research Program, Neuronal Networks Section, 251 Bayview Boulevard, Baltimore, MD 21224. E-mail: mmorales@intra.nida.nih.gov.

D0I:10.1523/JNEUROSCI.3428-15.2015

Copyright $\odot 2015$ the authors $\quad 0270-6474 / 15 / 3515948-07 \$ 15.00 / 0$ have shown that local activation of VTA dopaminergic neurons (Tsai et al. 2009; Witten et al., 2011; Ilango et al., 2014) or their terminals within the nucleus accumbens (nAcc; Steinberg et al., 2014) is rewarding. In contrast, activation of VTA GABAergic neurons is aversive (Tan et al., 2012), whereas their inhibition is rewarding (Jennings et al., 2013). Yet, activation of GABAergic terminals within the nAcc results in enhanced learning without effects on reward or aversion (Brown et al., 2012).

In addition to dopaminergic and GABAergic neurons, the VTA contains glutamatergic neurons expressing vesicular glutamate transporter-2 (VGluT2; Kawano et al., 2006; Yamaguchi et al., 2007, 2011). VTA VGluT2 neurons form both local connections (Dobi et al., 2010) and long-range connections within the prefrontal cortex, nAcc, lateral habenula (LHb), amygdala, and basal forebrain (Yamaguchi et al., 2011; Hnasko et al., 2012; Root et al., 2014a; Taylor et al., 2014; Zhang et al., 2015). Axon termi- 
nals from VTA VGluT2 neurons establish asymmetric (putative excitatory) synapses within the VTA (Dobi et al., 2010), LHb (Root et al., 2014a), and nAcc (Zhang et al., 2015). Slice electrophysiology recordings have shown that glutamate release from these terminals evokes EPSCs on VTA dopaminergic and nondopaminergic neurons (Dobi et al., 2010), nAcc medium spiny neurons (Hnasko et al., 2012; Zhang et al., 2015), or LHb neurons (Root et al., 2014a).

Due to anatomical and electrophysiological studies showing an excitatory pathway from local VTA VGluT2 neurons to local VTA neurons, we suggested previously that VTA glutamatergic neurons are part of an anticipated (and unexplored) local VTA microcircuitry (Dobi et al., 2010; Morales and Pickel, 2012). Here, we used a multidisciplinary approach to determine whether activation of VTA VGluT2 neurons participating in local circuitry plays a role in reward or aversion.

\section{Materials and Methods}

Animals. Animal procedures were performed in accordance with NIH guidelines and approved by the National Institute on Drug Abuse Animal Care and Use Committee. Male VGluT2::Cre mice were used (25-30 g body weight).

Surgical procedures. VGluT2::Cre mice were injected into the VTA with Cre-inducible recombinant AAV encoding Channelrhodopsin-2 (ChR2) tethered to enhanced yellow fluorescent protein (eYFP; VGluT2-ChR2eYFP mice) or mCherry (VGluT2-ChR2-mCherry mice). VGluT2::Cre mice injected with AAV tethered to eYFP (VGluT2-eYFP mice) served as controls. All viral injections were done as described by Root et al. (2014b). Mice were unilaterally implanted with ferrules or cannulas $10 \mathrm{~d}$ after injections.

Immunolabeling for confocal and electron microscopy analysis. Brain tissue for immunodetection of mCherry, VGluT2, and tyrosine hydroxylase (TH) were processed as described by Zhang et al. (2015).

Real-time place conditioning test. VGluT2-ChR2-eYFP and VGluT2eYFP mice were connected to an optical fiber, and mice freely accessed a three-chamber apparatus (for details, see Qi et al., 2014). On photostimulation conditioning days 1 and 2 (30 min sessions), we assigned one chamber as the stimulation-paired chamber. The mice were photostimulated $(473 \mathrm{~nm}, \sim 8 \mathrm{~mW}, 10 \mathrm{~ms}$ duration at $20 \mathrm{~Hz}$; training timeline, see Fig. 2A) in the VTA whenever they entered the photostimulation-paired chamber, and stimulation continued until the mouse left the chamber. Mice were not photostimulated on the test day.

Optical intracranial self-stimulation. VGluT2-ChR2-eYFP and VGluT2eYFP mice were placed in operant chambers equipped with two response wheels (left and right) for a daily $30 \mathrm{~min}$ self-stimulation test (for details, see Qi et al., 2014). Quarter-turns of one wheel (active wheel) caused a $0.5 \mathrm{~s}$ train of $20 \mathrm{~Hz}$ photostimulation $(473 \mathrm{~nm}, \sim 8 \mathrm{~mW}, 10 \mathrm{~ms}$ duration per pulse, 10 pulses). Responses on the other (inactive) wheel did not result in photostimulation. During the first 8 training days, the right wheel was designated as the active wheel; during the next 4 training days, the left wheel was the active wheel. A week later, VGluT2-ChR2-eYFP mice were retested in 30 min daily sessions at 10 pulses with $10 \mathrm{~ms}$ duration under different stimulation frequencies (see Fig. 3C). After 1 week, VGluT2-ChR2-eYFP mice were retested in 30 min daily sessions at $20 \mathrm{~Hz}$ under different stimulation pulses (see Fig. 3D). After behavioral tests, brain sections from tested mice were examined. Mice with out-oftarget cannula or probe implantation were excluded from the data analysis (Fig. 4).

Slice electrophysiology. Eight weeks after virus injection, the retrograde tracer cholera toxin B subunit $(\mathrm{CTb})$ was delivered into the nAcc of VGluT2::Cre-infected mice as detailed by Qi et al. (2014). A week later, VTA slices were obtained, and whole-cell recordings of CTb neurons were done as described by Qi et al. (2014).

VTA injections of glutamate receptor antagonists. For pharmacological studies, we injected into the VTA the NMDA receptor antagonist MK801 (catalog \#0924, Tocris Bioscience) or AMPA receptor antagonist
CNQX (catalog \#C239, Sigma-Aldrich; $0.2 \mu \mathrm{l}$ ) dissolved in artificial CSF (ACSF), as described by Qi et al. (2014).

Statistics. We performed one-, two-, or three-way ANOVA to analyze the behavioral data when applicable. When we obtained significant main or interaction effects, we performed Newman-Keuls post hoc tests for group comparisons. All statistical analyses were performed with STATISTICA 12. The level of significance was $p<0.05$.

\section{Results}

We showed previously the selective expression of Cre-recombinase under the regulation of the VGluT2 promoter in VTA neurons of VGluT2::Cre mice (Root et al., 2014b). Here, VGluT2::Cre mice were used to express either mCherry or eYFP alone or tethered to ChR2 in VTA VGluT2 neurons.

\section{Axon terminals from infected VTA VGluT2 neurons coexpress} $V G l u T 2$ protein and $m$ Cherry and establish asymmetric synapses on single dendrites of neighboring neurons

By immunofluorescence we verified induced expression of mCherry (or eYFP) confined to VTA neurons. VTA boundaries were determined by the presence of $\mathrm{TH}$ (Fig. 1A). Within the VTA, we detected mCherry in cell bodies and processes, but detected VGluT2 immunoreactivity only in varicosities (Fig. 1B), some of which coexpressed mCherry (Fig. 1C). By electron microscopy, we found that VTA varicosities coexpressing mCherry and VGluT2 (mCherry-VGluT2) corresponded to axon terminals establishing several asymmetric synapses on dendrites of local neurons (Fig. 1D). Some of these dendrites were TH positive (Fig. 1E). The glutamate release from local VTA VGluT2 neurons on dopaminergic neurons is suggested by the detection of VGluT2 protein (for the vesicular accumulation of glutamate and its synaptic release) in axon terminals (from VTA-infected neurons) that form asymmetric synapses on neighboring $\mathrm{TH}$ neurons. Thus, to confirm that $\mathrm{TH}$ neurons are excited by local glutamatergic neurons, and to determine whether these TH neurons innervate the nAcc, we performed whole-cell recordings in VTA slices from VGluT2-ChR2-mCherry mice injected with the retrograde tracer $\mathrm{CTb}$ in the nAcc. Optical-evoked currents were detected in 9 of $50 \mathrm{CTb}$ neurons (five mice) showing long action potential durations (1.9 to $4.0 \mathrm{~ms}$, values associated with $\mathrm{TH}$ neurons). EPSCs higher than $20 \mathrm{pA}$ and sensitive to the AMPA receptor antagonist CNQX were found in five of the nine $\mathrm{CTb}$ neurons, which were confirmed to be TH positive (Fig. $1 F, G$ ). Under current-clamp mode, these five neurons showed spontaneous tonic firing, the frequency of which was increased by trains of photostimulation $(20 \mathrm{~Hz}, 20$ pulses $)$, greatly attenuated by CNQX, and further eliminated by application of the NMDA receptor antagonist APV (Fig. $1 H, I$ ). Together, these findings indicate that (1) terminals from VTA VGluT2 neurons established asymmetric synapses on VTA dopaminergic neurons, (2) these terminals contained VGluT2 protein, and (3) local activation of VTA VGluT2 neurons increased firing of mesoaccumbens dopaminergic neurons (Fig. $1 J$ ).

\section{Photostimulation of VTA VGluT2 neurons caused conditioned} place preference mediated by VTA glutamate receptors

We tested whether photoactivation of VTA VGluT2 neurons resulted in conditioned place preference or aversion (Fig. 2A). Mice were tested in a three-chamber apparatus in which they received continuous trains of photostimulation each time that they entered the photostimulation-paired chamber. VGluT2-eYFP (control) mice spent similar time in the photostimulation-paired or the photostimulation-unpaired chamber, whereas VGluT2-ChR2eYFP mice spent significantly more time in the photostimulation- 

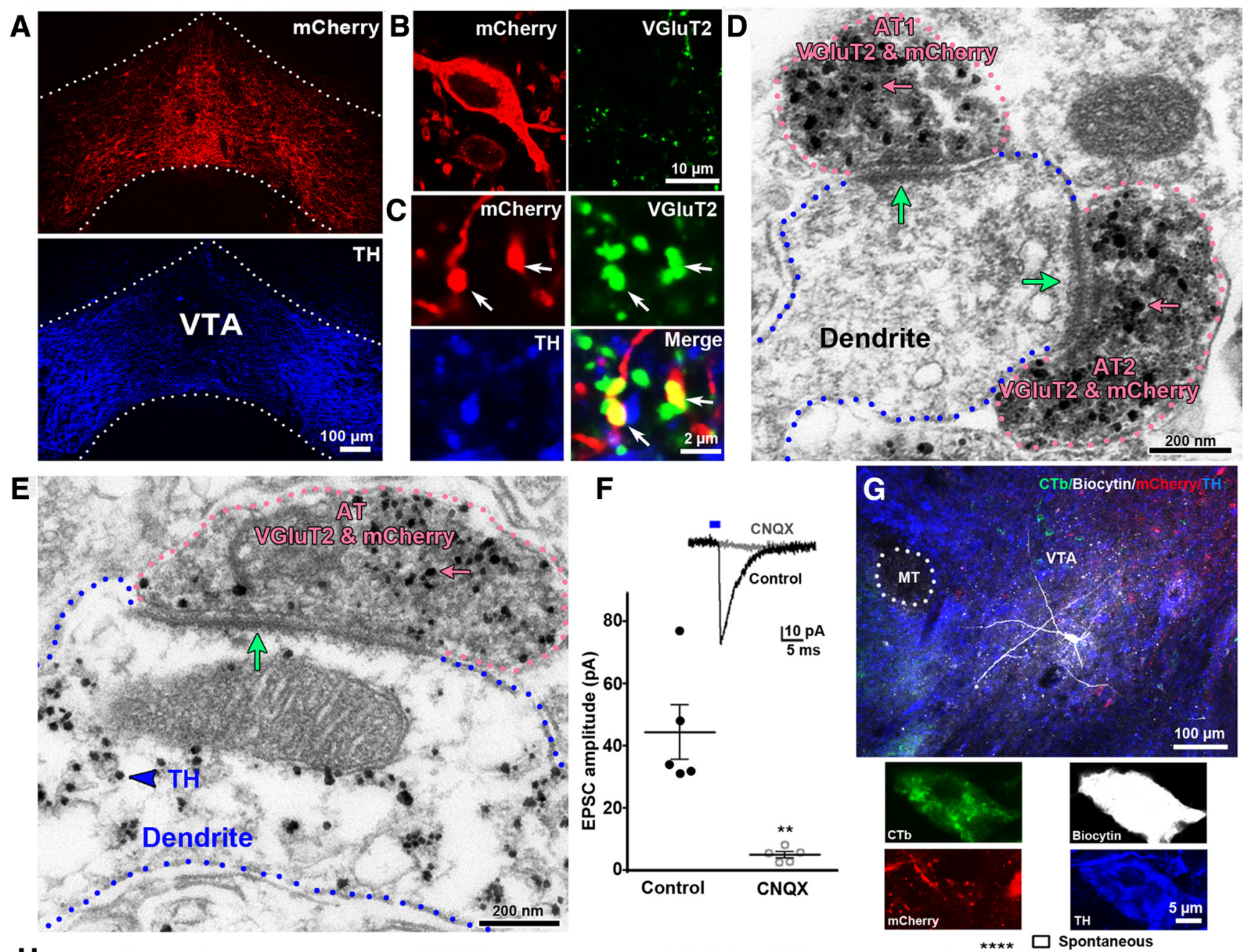

H

Control

CNQX
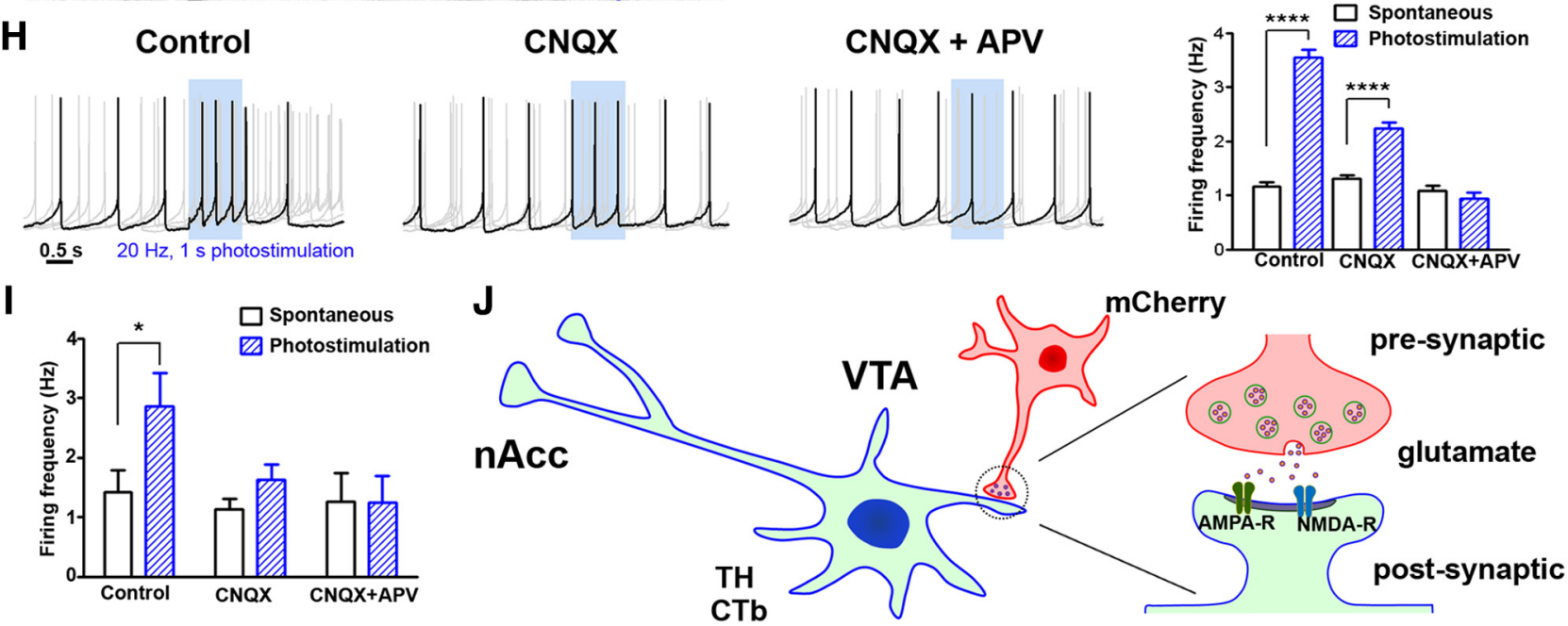

Figure 1. VTA VGluT2 neurons establish excitatory synapses on mesoaccumbens dopaminergic neurons. $\boldsymbol{A}$, Immunofluorescence microscopy showing mCherry expression (red) within the VTA (TH detection in blue). $\boldsymbol{B}$, High magnification showing mCherry in cell bodies and processes and VGluT2 (green) in varicosities. $\boldsymbol{C}$, Higher magnification showing mCherry in axons and VGluT2 in varicosities, some of them coexpressing mCherry (arrows). D, E, Electron microscopy. D, Two axon terminals (AT1 and AT2) coexpressing VGluT2 (gold particles, pink arrows) and mCherry (scattered dark material) making asymmetric synapses (green-arrows) on a common dendrite (blue outline). $\boldsymbol{E}$, An mCherry-VGluT2 terminal making an asymmetric synapse (green arrow) with a dendrite expressing TH (blue arrowhead). $\boldsymbol{F}$, Photostimulation of VTA VGluT2 fibers evoked CNQX-sensitive EPSCs in mesoaccumbens dopaminergic neurons. The graph summarizes CNQX blockade ( $N=5$ neurons; paired $t$ test, $\left.{ }^{* *} p<0.01\right)$. The lines represent mean \pm SEM. $\boldsymbol{G}$, Recorded mesoaccumbens TH-positive neuron. MT, Medial terminal nucleus of the accessory optic tract. $\boldsymbol{H}$, Photostimulation (blue area) increased the firing frequency, which was attenuated by CNQX (10 $\mu \mathrm{m}$ ) and eliminated by further application of APV (50 $\mu \mathrm{m})$. The graph summarizes the firing frequency of this mesoaccumbens neuron (paired $t$ test, ${ }^{* * * *} p<0.0001$ ). The bars represent mean $+S E M$. $I$, The graph summarizes the firing frequency changes from five mesoaccumbens neurons (paired $t$ test, ${ }^{*} p<0.5$ ). The bars represent mean + SEM. J, Diagram of VTA glutamatergic neuron synapsing on mesoaccumbens dopaminergic neuron. 


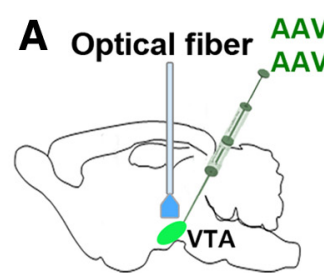

VGIUT2::Cre mice
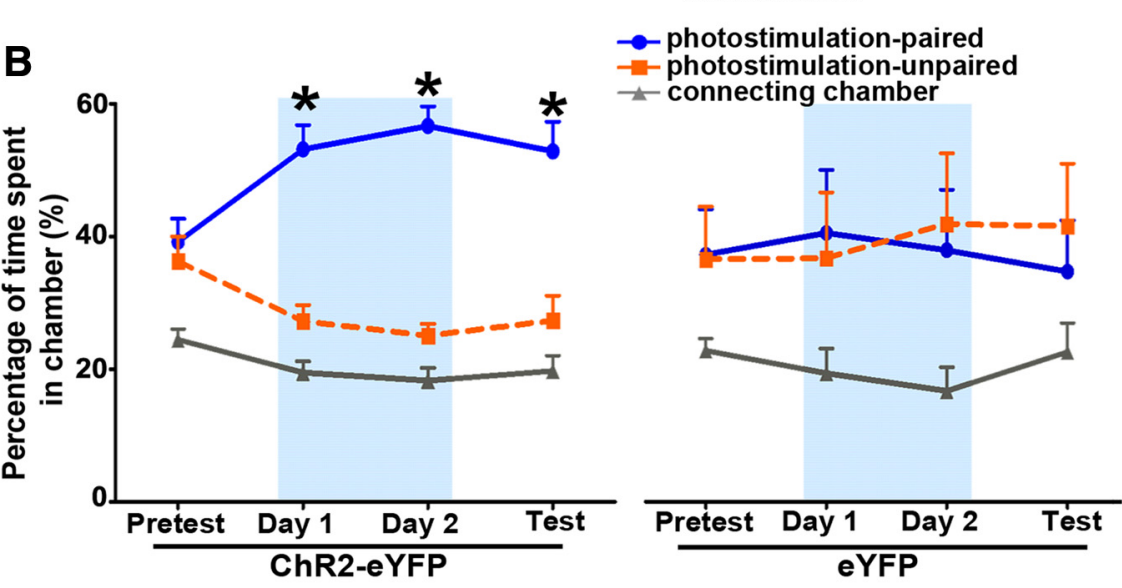

C

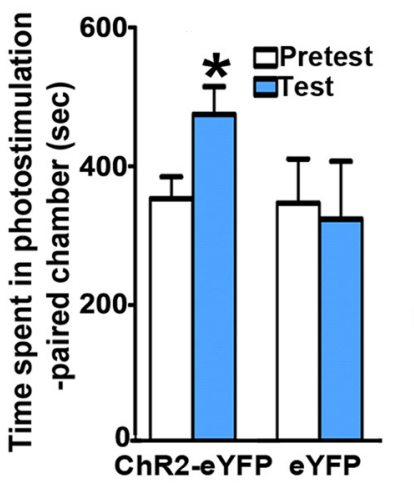

D

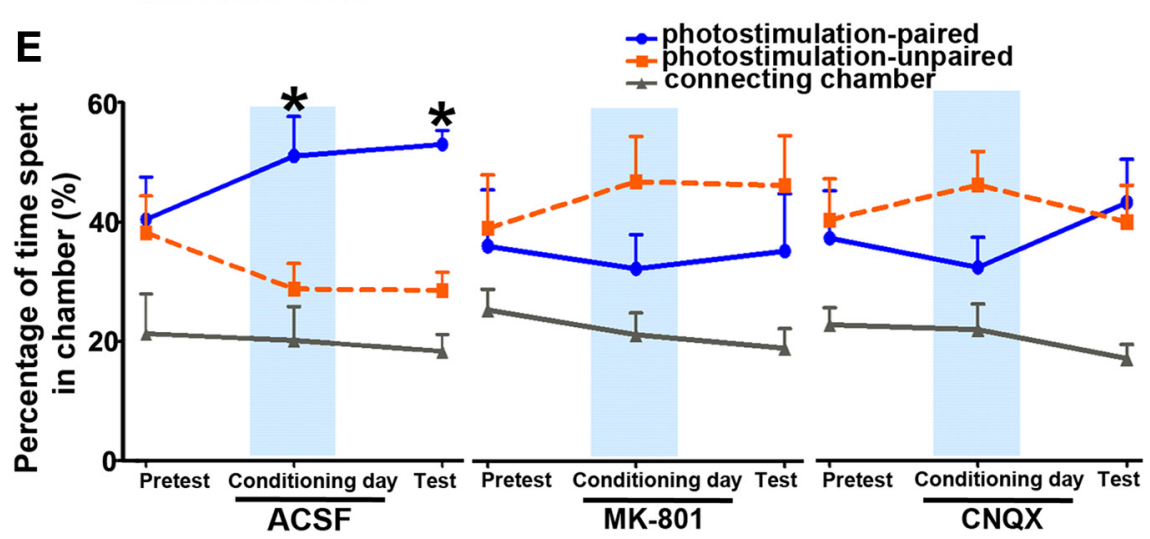

Figure 2. Photostimulation of VTA VGluT2 neurons evokes conditioned place preference mediated by VTA glutamate receptors. A, VTA virus injection (VGIUT2::Cre mice), photostimulation of VTA VGluT2 neurons, and experimental timeline. $\boldsymbol{B}$, VGluT2-ChR2eYFP, but not VGluT2-eYFP, mice sought out and spent more time in the chamber where VTA photostimulation was delivered during training. On the test day, VGluT2-ChR2-eYFP mice returned to and spent more time in the chamber where photostimulation was given on the previous day compared with VGIUT2-eYFP controls (group by day by chamber interaction, $F_{(6,84)}=3.19, p<$ 0.01, three-way ANOVA). The relative time spent in each chamber is shown (mean + SEM; VGluT2-ChR2-eYFP mice, $N=10$; VGluT2-eYFP mice, $N=6$ ). Blue rectangles indicate available photostimulation in the photostimulation-paired chamber. VGluT2ChR2-eYFP mice showed a preference for the photostimulation-paired chamber on both conditioning days and the test day $\left({ }^{*} p<\right.$ 0.001 , Newman-Keuls post hoc test). C, Time that mice spent in photostimulation-paired chamber on the pretest day and test day. Bars represent the mean + SEM. After two photostimulation-paired sessions, VGluT2-ChR2-eYFP mice spent significantly more time in the photostimulation-paired chamber on the test day compared with the pretest day and VGluT2-eYFP controls (group by paired chamber $(p<0.01$; Fig. $2 B)$. When VGluT2-ChR2-eYFP mice were subsequently tested in the absence of photostimulation, they spent more time in the chamber where they had previously received photostimulation $(p<0.001$; Fig. $2 B, C)$. These results indicate that VGluT2-ChR2-eYFP mice not only earned the photostimulation by entering the stimulation chamber when photostimulation was available, but they also acquired a preference for the photostimulation-paired chamber as reflected by the time spent there on the subsequent day, when the photostimulation was no longer available.

Next, we evaluated the involvement of VTA glutamate receptors in real-time place preference, evoked by photostimulation of VTA VGluT2 neurons, by VTA injections of NMDA receptor antagonist (MK-801) or AMPA receptor antagonist (CNQX) on the conditioning day (Fig. $2 D, E)$. Mice that received a VTA injection of ACSF showed preference to the laserpaired chamber on both the photostimulation training day and the test day $(p<$ 0.05 ; Fig. 2E). By contrast, mice that received a VTA injection of MK-801 or CNQX did not show preference for the photostimulation-paired chamber either on the photostimulation training day or on the test day (Fig. 2E). These findings indicate that the VTA VGluT2 neurons mediate the development of place preference by releasing glutamate into the VTA, resulting in activation of both NMDA and AMPA receptors.

Photostimulation of VTA VGluT2 neurons served as an instrumental reinforcement mediated by VTA glutamate-receptors To further characterize the rewarding properties of photoactivation of VTA VGlu T2 neurons, we next determined whether photoactivation of these neurons supports instrumental responding. VGluT2-ChR2-

day interaction, $F_{(1,14)}=6.21,{ }^{*} p<0.05$, three-way ANOVA following by Newman-Keuls post hoc test). D, Experimental timeline showing virus injection, VTA injections of NMDA receptor antagonist (MK-801) or AMPA receptor antagonist (CNQX), and VTA photostimulation of VGluT2 neurons. E, VTA injection of MK-801 (1.7 $\mu \mathrm{g}, N=6)$ or CNQX (1 $\mu \mathrm{g}, N=7)$ blocked conditioned preference for the photostimulationpaired chamber (group by chamber interaction, $F_{(4,44)}=1.99$, $p>0.05$, three-way ANOVA). The relative time spent (mean + SEM) in each chamber by VGluT2-ChR2-eYFP mice receiving a single VTA microinjection of ACSF $(N=11)$, MK-801, or CNQX 15 min before photostimulation conditioning is shown. VTA injected mice with ACSF showed preference for photostimulation-paired chamber on the conditioning day $\left(F_{(2,20)}=7.87,{ }^{*} p<0.05\right.$, one-way ANOVA $)$ and the test day $\left(F_{(2,20)}=7.54,{ }^{*} p<0.05\right.$, one-way ANOVA). 


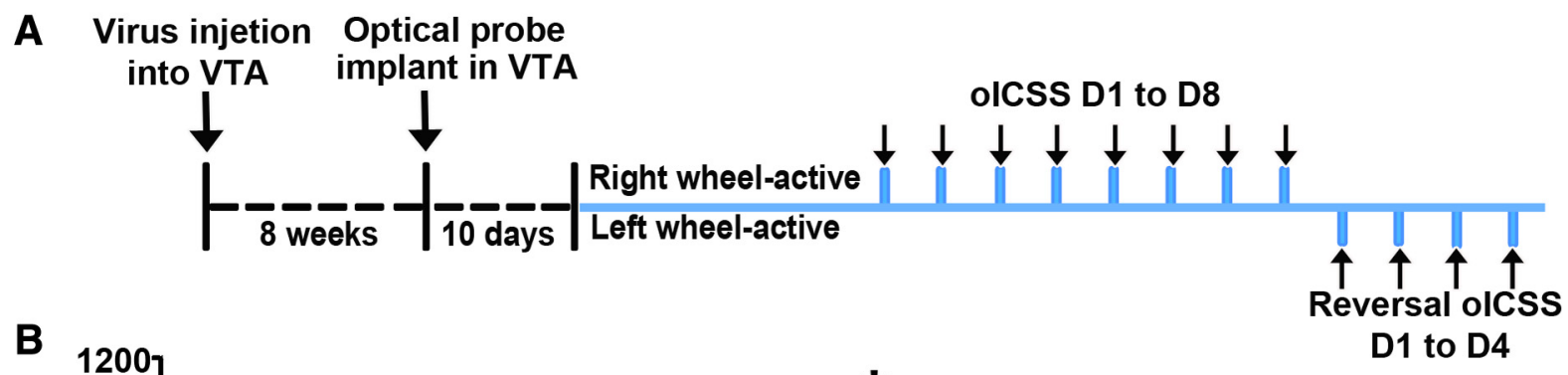

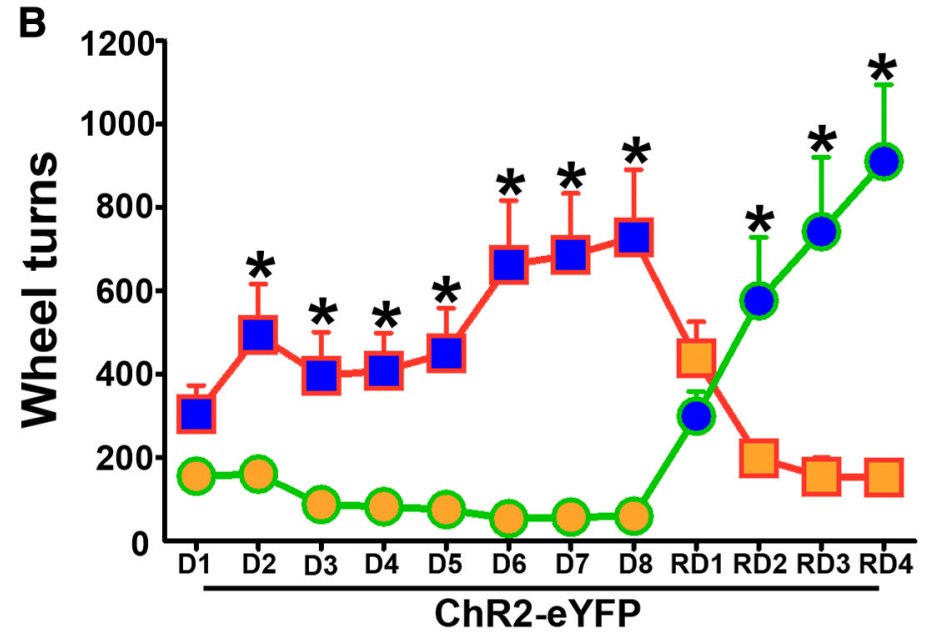

C

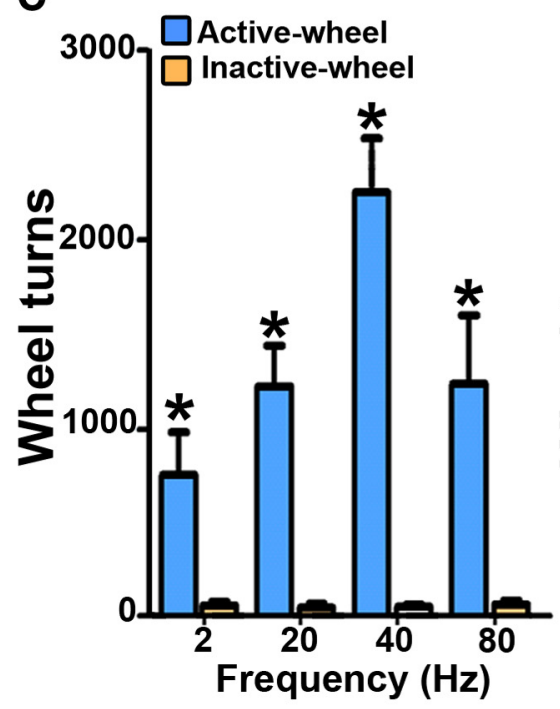

D

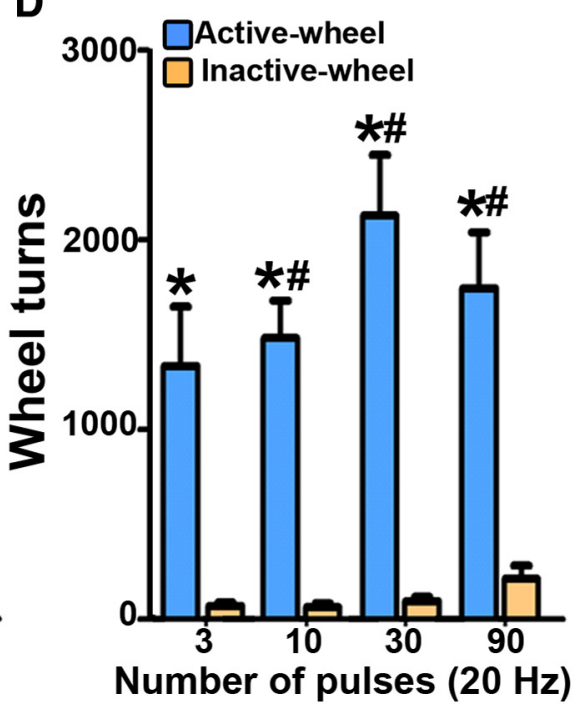

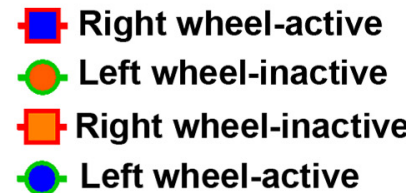

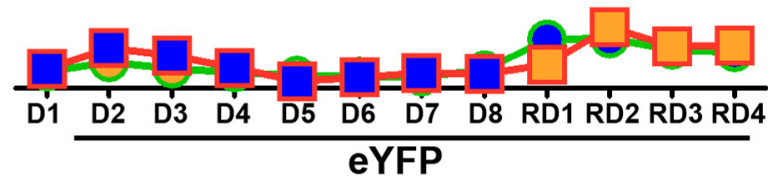

E

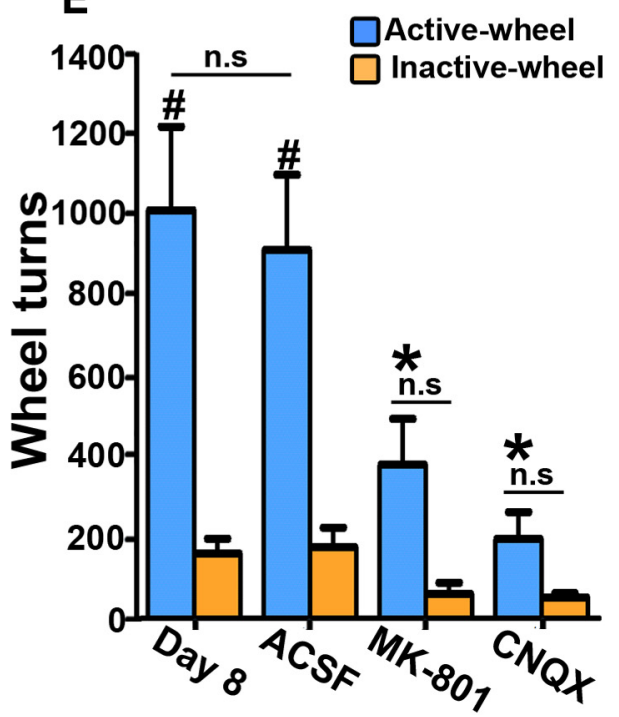

Figure 3. Mice learn a wheel-turning response for photostimulation of VTA VGluT2 neurons mediated by VTA glutamate receptors. $A$, Timeline for the olCSS procedure: $8 \mathrm{~d}$ of olCSS sessions (D1-D8; right wheel results in photostimulation; active wheel) and $4 \mathrm{~d}$ of reversal olCSS sessions (RD1-RD4; left wheel results in photostimulation). $\boldsymbol{B}$, Mean number (mean + SEM) of wheel turns in each session. VGIuT2-ChR2-eYFP mice $(N=8)$ rotated the active wheel significantly more than the inactive wheel (day by wheel interaction, $F_{(11,143)}=6.94,{ }^{*} p<0.001$, three-way ANOVA with Newman-Keuls post hoc test), and significantly more than the VGluT2-eYFP mice $(N=7)$, during the $8 \mathrm{~d}$ of olCSS sessions and the $4 \mathrm{~d}$ of reversal olCSS sessions (group, $\left.F_{(1,13)}=18.24, p<0.001\right)$. C, VGIuT2-ChR2-eYFP mice $(N=8)$ rotated the active wheel significantly more than the inactive wheel at all tested frequencies $\left(F_{(1,11)}=31.83,{ }^{*} p<0.01\right.$ vs inactive wheel). Mice rotated the active wheel more times at $40 \mathrm{~Hz}$, but there was not a significant difference among frequency variation (frequency by wheel interaction, $\left.F_{(3,33)}=1.789, p>0.05\right)$. $D, V G l u T 2$-ChR2-eYFP mice $(N=4)$ rotated the active wheel significantly more times than the inactive wheel at all tested pulses $\left(F_{(1,11)}=74.293,{ }^{*} p<0.01\right.$ vs inactive wheel), with the lowest response at three pulses of stimulation

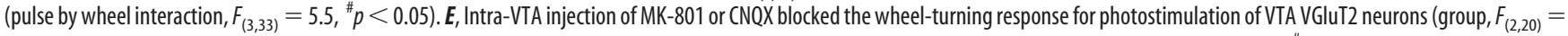
$8.75,{ }^{*} p<0.01$ vs ACSF group). Intra-VTA ACSF injected mice rotated the active wheel significantly more times than the inactive wheel on the training day ( $\left.{ }^{\#} p<0.001\right)$, and there was not a significant difference in wheel turning before (day 8$)$ and after ACSF injection $\left(F_{(1,14)}=0.077, p>0.05\right)$. Mice received a single intra-VTA microinjection of ACSF $(0.2 \mu l, N=8)$, MK-801 (1.7 $\mu$, $N=8)$, or CNQX (1 $\mu \mathrm{g}, N=7) 15$ min before photostimulation. Data are presented as mean + SEM, analyzed by two-way ANOVA with Newman-Keuls post hoc test.

eYFP or VGluT2-eYFP mice were placed in chambers in which they were allowed to earn VTA photostimulation by rotating response wheels; a quarter-turn of one of the wheels (active wheel) resulted in photostimulation of VTA VGluT2 neurons (a $0.5 \mathrm{~s}$ train of $10 \mathrm{~ms}$ light pulses, $20 \mathrm{~Hz}$ ). During a first period of eight daily optical intracranial self-stimulation (oICSS) training sessions (D1 to D8), the right wheel was designated as the active wheel (Fig. 3A). VGluT2ChR2-eYFP mice rotated the active wheel significantly more times than the inactive wheel from the second and subsequent sessions (Fig. 3B), and significantly more than VGluT2-eYFP mice turned either wheel $(p<0.001 ;$ Fig. $3 B)$. To confirm that the frequency of wheel turning reflects the rewarding effect of the stimulation, we 
A

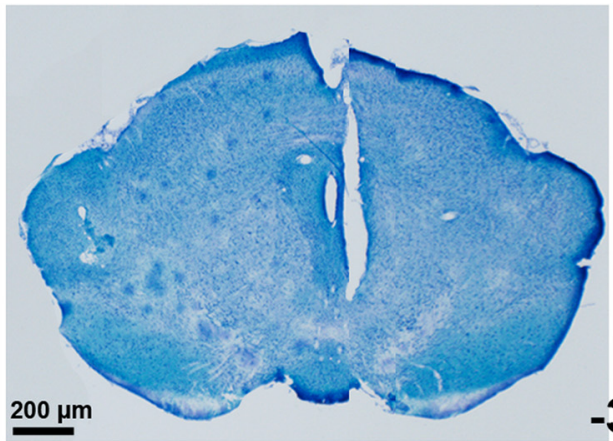

B

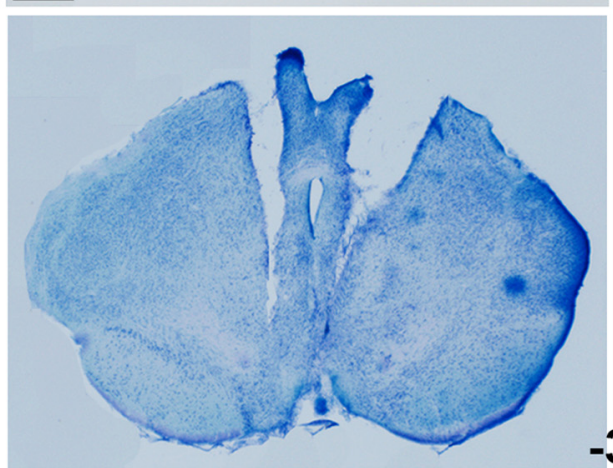

$-3.28 \mathrm{~mm}$

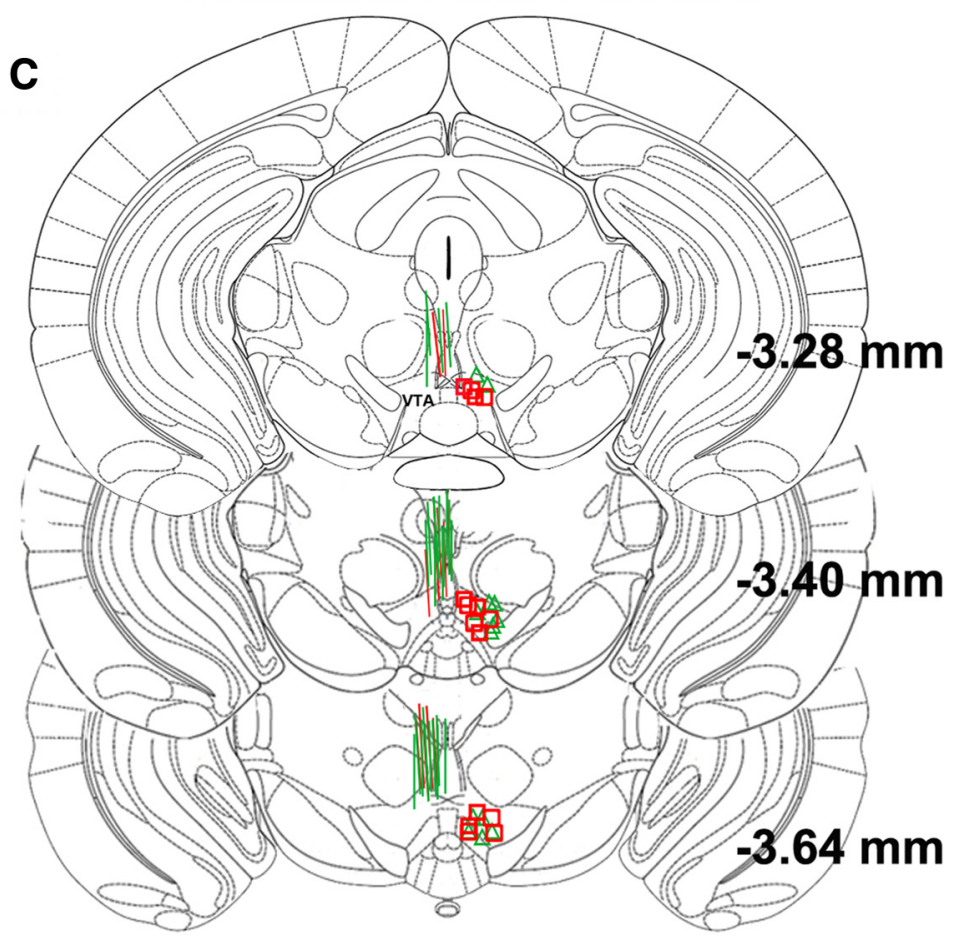

Figure 4. Localizations of optical fibers or microinjection tips in VGluT2::Cre mouse. A, Representative optical fiber track in (Bregma $-3.40 \mathrm{~mm}$ ). $\boldsymbol{B}$, Representative microinjection cannula track (right) and probe track (left) in VTA (Bregma $-3.28 \mathrm{~mm}$ ). C, Schematic brain drawings show optical fiber placements in VTA. Green, VGluT2-ChR2-eYFP mice; red, VGluT2-eYFP mice. Microinjection tips in VTA are indicated by green triangles (conditioned place preference experiments) and red squares (olCSS experiments).

then switched the position of the active wheel for $4 \mathrm{~d}$ of reversal training (reversal D1 to D4) and found that VGluT2-ChR2eYFP mice quickly changed their preference to the new active wheel on the second reversal training day (Fig. 3B). We next tested different frequencies and pulses of photostimulation and found that frequencies of 2, 20, and $40 \mathrm{~Hz}$ were increasingly effective in evoking oICSS, but decreasingly effective at $80 \mathrm{~Hz}$ (Figure $3 C$ ). Photostimulations with 3, 10, 30, or 90 pulses at $20 \mathrm{~Hz}$ evoked oICSS (Fig. 3D).
Finally, we evaluated the involvement of VTA glutamate receptors in the instrumental responding caused by photostimulation of VTA VGluT2 neurons. We found that the number of active wheel turns evoked by photostimulation of VTA VGluT2 neurons was significantly inhibited by VTA injection of either MK-801 or CNQX ( $p<0.01$ vs ACSF group; Fig. $3 E$ ), but did not significantly decrease the number of inactive wheel turns compared with ACSF group ( $p>0.05$; Fig. $3 E)$. These findings indicate that instrumental responding evoked by activation of VTA VGluT2 neurons is mediated by local AMPA and NMDA receptors.

\section{Discussion}

Local VTA cellular photoactivation versus photoactivation of their long-range fibers Emerging evidence indicates that different behaviors may be elicited by photoactivation of VTA local neurons versus photoactivation of their long-range fibers. We and others have shown that LHb photoactivation of mesohabenular fibers expressing ChR2 under the VGluT2 promoter elicits glutamate receptormediated conditioned place aversion and promotes aversive conditioning (Root et al., 2014b; Lammel et al., 2015). In contrast, we report here that photoactivation of VTA VGluT2 neurons expressing ChR2 under VGluT2 promoter causes conditioned place preferences and also reinforces instrumental behavior. Whereas these rewarding effects were driven under different parameters of VTA photoactivation, the tested parameters did not result in any observable aversion. In addition, we determined that VTA local activation of glutamate receptors was necessary for both conditioned place preferences and instrumental responding.

We propose that the observed rewarding effects induced by photoactivation of VTA VGluT2 neurons are due, in part, to the release of glutamate from terminals that establish local excitatory synapses on mesoaccumbens dopaminergic neurons. In clear contrast, LHb photoactivation of terminals from VTA VGluT2 neurons is aversive (Root et al., 2014b; Lammel et al., 2015). In this regard, it is important to make the distinction that although we demonstrated that photoactivation of VTA VGluT2 neurons results in the activation of local glutamatergic receptors, it is unclear whether the same parameters of photoactivation also result in the activation of glutamate receptors in the LHb or other brain areas outside the VTA, some of which may also participate in reward or in overriding the aversive effects induced by activation of LHb glutamatergic receptors. 
As reward and aversive conditioning differs by photoactivation of VTA glutamatergic intrinsic or extrinsic fibers, different behaviors appear to be elicited by local photoactivation of VTA GABAergic neurons or their long-range terminals. While photoactivation of VTA GABAergic neurons causes conditioned place aversion (Tan et al. 2012), nAcc photoactivation of fibers from VTA GABAergic neurons plays a role in reward consumption (van Zessen et al., 2012) and a role in associative learning (Brown et al., 2012). On the other hand, LHb photoactivation of fibers from VTA GABAergic neurons is rewarding (Stamatakis et al., 2013). These findings indicate that different behaviors may be elicited by either local activation of VTA GABAergic neurons or their long-range fibers.

\section{Heterogeneity among VTA glutamate neurons}

The VTA VGluT2 neurons are diverse in their molecular composition, signaling properties, and neuronal connectivity (Morales and Root, 2014). While the majority of rat and mouse VTA VGluT2 neurons lack both dopaminergic and GABAergic markers, there are subpopulations of VTA VGluT2 neurons that coexpress molecules responsible for the synthesis or the vesicular transport of either dopamine or GABA (Li et al., 2013; Root et al., 2014a; Yamaguchi et al., 2015). Anatomical and electrophysiological studies have shown that some of the VTA VGluT2 neurons coexpressing TH (VGluT2-TH neurons) innervate the nAcc and evoke EPSCs on medium spiny neurons (Stuber et al., 2010; Tecuapetla et al., 2010; Zhang et al., 2015). Previous findings have provided evidence for dopamine and glutamate release from segregated microdomains within a single VGluT2-TH mesoaccumbens axon (Zhang et al., 2015). Another subset of VTA VGluT2 neurons has been shown to express GABA markers (VGluT2GABA neurons) and innervate LHb (Root et al., 2014a). LHb photoactivation of fibers from these VGluT2-GABA neurons results in the corelease of glutamate and GABA from the same axon terminal (Root et al., 2014a). While these findings provide evidence for cotransmission by some VTA glutamatergic neurons, it remains to be determined whether some VTA VGluT2-TH or VTA VGluT2-GABA neurons are also part of the VTA local circuitry.

In summary, we provide converging evidence for the existence of a VTA excitatory microcircuitry by local glutamatergic neurons in which activation of these neurons promotes glutamate receptor-mediated conditioned place preference and appetitive instrumental conditioning. We suggest that this microcircuitry is likely to participate in the VTA integration of information from brain areas innervating the VTA and in modulating VTA output neurotransmission

\section{References}

Brown MT, Tan KR, O'Connor EC, Nikonenko I, Muller D, Lüscher C (2012) Ventral tegmental area GABA projections pause accumbal cholinergic interneurons to enhance associative learning. Nature 492: 452-456. CrossRef Medline

Dobi A, Margolis EB, Wang HL, Harvey BK, Morales M (2010) Glutamatergic and nonglutamatergic neurons of the ventral tegmental area establish local synaptic contacts with dopaminergic and nondopaminergic neurons. J Neurosci 30:218-229. CrossRef Medline

Hnasko TS, Hjelmstad GO, Fields HL, Edwards RH (2012) Ventral tegmental area glutamate neurons: electrophysiological properties and projections. J Neurosci 32:15076-15085. CrossRef Medline

Ilango A, Kesner AJ, Keller KL, Stuber GD, Bonci A, Ikemoto S (2014) Similar roles of substantia nigra and ventral tegmental dopamine neurons in reward and aversion. J Neurosci 34:817-822. CrossRef Medline

Jennings JH, Sparta DR, Stamatakis AM, Ung RL, Pleil KE, Kash TL, Stuber
GD (2013) Distinct extended amygdala circuits for divergent motivational states. Nature 496:224-228. CrossRef Medline

Kawano M, Kawasaki A, Sakata-Haga H, Fukui Y, Kawano H, Nogami H, Hisano S (2006) Particular subpopulations of midbrain and hypothalamic dopamine neurons express vesicular glutamate transporter 2 in the rat brain. J Comp Neurol 498:581-592. CrossRef Medline

Lammel S, Steinberg EE, Földy C, Wall NR, Beier K, Luo L, Malenka RC (2015) Diversity of transgenic mouse models for selective targeting of midbrain dopamine neurons. Neuron 85:429-438. CrossRef Medline

Li X, Qi J, Yamaguchi T, Wang HL, Morales M (2013) Heterogeneous composition of dopamine neurons of the rat A10 region: molecular evidence for diverse signaling properties. Brain Struct Funct 218:1159-1176. CrossRef Medline

Morales M, Pickel VM (2012) Insights to drug addiction derived from ultrastructural views of the mesocorticolimbic system. Ann N Y Acad Sci 1248:71-88. CrossRef

Morales M, Root DH (2014) Glutamate neurons within the midbrain dopamine regions. Neuroscience 282C:60-68. Medline

Qi J, Zhang S, Wang HL, Wang H, de Jesus Aceves Buendia J, Hoffman AF, Lupica CR, Seal RP, Morales M (2014) A glutamatergic reward input from the dorsal raphe to ventral tegmental area dopamine neurons. Nat Commun 5:5390. CrossRef Medline

Root DH, Mejias-Aponte CA, Zhang S, Wang HL, Hoffman AF, Lupica CR, Morales M (2014a) Single rodent mesohabenular axons release glutamate and GABA. Nat Neurosci 17:1543-1551. CrossRef Medline

Root DH, Mejias-Aponte CA, Qi J, Morales M (2014b) Role of glutamatergic projections from ventral tegmental area to lateral habenula in aversive conditioning. J Neurosci 34:13906-13910. CrossRef Medline

Stamatakis AM, Jennings JH, Ung RL, Blair GA, Weinberg RJ, Neve RL, Boyce F, Mattis J, Ramakrishnan C, Deisseroth K, Stuber GD (2013) A unique population of ventral tegmental area neurons inhibits the lateral habenula to promote reward. Neuron 80:1039-1053. CrossRef Medline

Steinberg EE, Boivin JR, Saunders BT, Witten IB, Deisseroth K, Janak PH (2014) Positive reinforcement mediated by midbrain dopamine neurons requires D1 and D2 receptor activation in the nucleus accumbens. PLoS One 9:e94771. CrossRef Medline

Stuber GD, Hnasko TS, Britt JP, Edwards RH, Bonci A (2010) Dopaminergic terminals in the nucleus accumbens but not the dorsal striatum corelease glutamate. J Neurosci 30:8229-8233. CrossRef Medline

Tan KR, Yvon C, Turiault M, Mirzabekov JJ, Doehner J, Labouèbe G, Deisseroth K, Tye KM, Lüscher C (2012) GABA neurons of the VTA drive conditioned place aversion. Neuron 73:1173-1183. CrossRef Medline

Taylor SR, Badurek S, Dileone RJ, Nashmi R, Minichiello L, Picciotto MR (2014) GABAergic and glutamatergic efferents of the mouse ventral tegmental area. J Comp Neurol 522:3308-3334. CrossRef Medline

Tecuapetla F, Patel JC, Xenias H, English D, Tadros I, Shah F, Berlin J, Deisseroth K, Rice ME, Tepper JM, Koos T (2010) Glutamatergic signaling by mesolimbic dopamine neurons in the nucleus accumbens. J Neurosci 30:7105-7110. CrossRef Medline

Tsai HC, Zhang F, Adamantidis A, Stuber GD, Bonci A, de Lecea L, Deisseroth K (2009) Phasic firing in dopaminergic neurons is sufficient for behavioral conditioning. Science 324:1080-1084. CrossRef Medline

van Zessen R, Phillips JL, Budygin EA, Stuber GD (2012) Activation of VTA GABA neurons disrupts reward consumption. Neuron 73:1184-1194. CrossRef Medline

Witten IB, Steinberg EE, Lee SY, Davidson TJ, Zalocusky KA, Brodsky M, Yizhar O, Cho SL, Gong S, Ramakrishnan C, Stuber GD, Tye KM, Janak PH, Deisseroth K (2011) Recombinase-driver rat lines: tools, techniques, and optogenetic application to dopamine-mediated reinforcement. Neuron 72:721-733. CrossRef Medline

Yamaguchi T, Sheen W, Morales M (2007) Glutamatergic neurons are present in the rat ventral tegmental area. Eur J Neurosci 25:106-118. CrossRef Medline

Yamaguchi T, Wang HL, Li X, Ng TH, Morales M (2011) Mesocorticolimbic glutamatergic pathway. J Neurosci 31:8476-8490. CrossRef Medline

Yamaguchi T, Qi J, Wang HL, Zhang S, Morales M (2015) Glutamatergic and dopaminergic neurons in the mouse ventral tegmental area. Eur J Neurosci 41:760-772. CrossRef Medline

Zhang S, Qi J, Li X, Wang HL, Britt JP, Hoffman AF, Bonci A, Lupica CR, Morales M (2015) Dopaminergic and glutamatergic microdomains in a subset of rodent mesoaccumbens axons. Nat Neurosci 18:386-392. CrossRef Medline 